\title{
Los deberes del personal al servicio de las Administraciones Públicas*
}

\author{
Jaime Rodríguez-Arana Muñoz \\ Catedrático de Derecho Administrativo de la \\ Universidad de A Coruña
}

\begin{abstract}
SUMARIO: I. INTRODUCCIÓN. II. EL DERECHO DE LA FUNCIÓN PÚBLICA EN EL MARCO CONSTITUCIONAL. III. DERECHOS Y DEBERES DEL PERSONAL AL SERVICIO DE LAS ADMINISTRACIONES PÚBLICAS. IV. SOBRE LOS DEBERES. V. EL ACATAMIENTO A LA CONSTITUCIÓN. VI. OBEDIENCIA Y COLABORACIÓN. VII. RESIDENCIA. VIII. CUMPLIMIENTO DE LA JORNADA. IX. SIGILO Y SECRETO PROFESIONAL. X. LOS DEBERES EN EL INFORME DE LA COMISIÓN DE EXPERTOS SOBRE EL ESTATUTO DE LA FUNCIÓN PÚBLICA. XI. REFLEXIÓN CONCLUSIVA.
\end{abstract}

\section{INTRODUCCIÓN}

Los deberes del personal al servicio de las Administraciones públicas constituye un tema central del derecho de la función pública. Forma parte del "nonnato" estatuto de la función pública, que tiene su encaje constitucional precisamente en la referencia que hace la Carta Magna en el artículo 103. 3 a que "la Ley regulará el estatuto de los funcionarios públicos". En el caso del personal laboral, la fuente a la que dirigirse se encuentra en los convenios colectivos y en el estatuto de los trabajadores. En todo caso, en esta materia de los deberes, no debiera haber mayores diferencias porque se trata de obligaciones derivadas del trabajo al servicio objetivo del interés general en ambos casos.

\footnotetext{
* Texto de la conferencia impartida por su autor en el CEMCI de Granada el día 14 de octubre de 2005 .
} 
Es poco, muy poco, lo que nos dice la Constitución sobre el particular. Por tanto, mientras no se apruebe el famoso estatuto, habrá que atender a la vieja Ley de funcionarios de 1964, adaptada a la vigente Constitución, en la que encontramos varios preceptos relativos a los deberes de los funcionarios públicos e interpretarlos en sentido amplio para todo el personal.

En cualquier caso, a lo largo de esta exposición, intentaremos contextualizar el llamado derecho de la función pública desde la perspectiva constitucional, analizaremos el sentido y funcionalidad de los deberes del personal al servicio de las Administraciones públicas en sus líneas generales, para terminar estudiando algunos deberes en particular y el tratamiento del tema por la comisión de expertos creada por el Gobierno en relación con el proyecto de estatuto de los empleados públicos. Finalmente, unos comentarios a modo de reflexión final.

Ciertamente, en el mundo en que vivimos no está de moda, en manera alguna, tratar sobre deberes ya que el ambiente que nos rodea es un ambiente compulsivamente centrado en los derechos, en las reclamaciones, en las reivindicaciones. Ordinariamente, debido quizás a la incongruencia, incoherencia o hipocresía que caracteriza al tiempo presente, la temática que hoy nos ocupa es contemplada desde una cierta crisis del principio de jerarquía, como si la teoría de los deberes fuera algo propio de tiempos pasados en que la función pública estaba inspirada en una mentalidad castrense, de naturaleza militar. Hoy, por el contrario, se suele apostar por los derechos, por las situaciones jurídicas del personal, que va a permitir disfrutar de determinadas relaciones jurídicas laborales y sociales, olvidando en alguna medida la esencia de la propia función pública: el servicio objetivo al interés general.

Por todo ello, es necesario señalar, ahora que estamos comenzando la exposición, que desde el marco constitucional, la función pública es una función de servicio objetivo al interés general en la que el personal es fundamental en orden a la consecución de este mandato constitucional. Claro, el servicio tampoco hoy está bien visto; más bien tiene una carga peyorativa que pareciera chocar con la necesidad imperiosa de realización personal a través del ejercicio de los derechos que son propios al personal al servicio de la Administración pública.

Sin embargo, bien sabemos que derechos y deberes son dos caras de la misma moneda. En este sentido, desde los postulados con los que acostumbro a trabajar en mis estudios e investigaciones de ciencias sociales: pensamiento abierto, plural, dinámico y complementario, nos encontramos que las exigen- 
cias del equilibrio que habita en las instituciones de la función pública nos conduce a tener muy presente esta necesaria ponderación entre ambos aspectos para entender cabalmente lo que es esencial de la función pública.

\section{EL DERECHO DE LA FUNCIÓN PÚBLICA EN EL MARCO CONSTITUCIONAL}

Las instituciones del Derecho Administrativo deben explicarse desde los valores, contenidos y parámetros de la Constitución. Así, entre otras cosas, se expresaba MAYER en su famosa sentencia: "el Derecho Constitucional pasa , el Derecho Administrativo permanece", quizás para subrayar la relevancia del marco y, a su vez, la esencia, a la vez relativa y estable, del Derecho Administrativo y sus instituciones, conceptos y categorías. Cambian los modelos políticos, los modelos de Estado, pero siempre nos toparemos con la necesidad de aplicar, de ejecutar las prescripciones del legislador de turno a la realidad. Quizás también por ello el magistrado WERNER señalara hace muchos años que, en definitiva, el Derecho Administrativo no era más que Derecho constitucional concretado, materializado en la cotidianeidad.

Desde este punto de vista, siguiendo al profesor MEILÁN, es cada vez más importante subrayar la tarea de situar el contexto constitucional del Derecho Administrativo como primera providencia para estudiar el régimen de la institución, concepto o categoría de que se trate. Por eso, la denominación Derecho Administrativo Constitucional ayuda al menos a entender la necesidad de analizar el estudio de todas las instituciones desde la luz constitucional y, a partir de ahí, comprobar que la regulación concreta se construye desde los principios constitucionales.

Ciertamente, la Constitución sólo dedica un precepto a la función pública en sentido estricto, el 103, especialmente en su párrafo tercero:

"La ley regulará el estatuto de los funcionarios públicos, el acceso a la función pública de acuerdo con los principios de mérito y capacidad, las peculiaridades del ejercicio de su derecho a sindicación, el sistema de incompatibilidades y las garantías para la imparcialidad en el ejercicio de sus funciones"

Este parágrafo debe enmarcarse en la función constitucional de la Administración pública: el servicio objetivo al interés general, de forma y manera que la teoría de los deberes de los funcionarios será un desarrollo armónico y 
lógico de la tarea constitucional del personal al servicio de las Administraciones públicas: el servicio objetivo al interés general. Es más, me atrevería a afirmar que el conjunto de los deberes ha de partir de este objetivo constitucional.

Por otra parte, debe señalarse que el párrafo segundo del artículo 103 se refiere, en sede de estatuto, a los funcionarios, sin citar otras modalidades de personal al servicio de las Administraciones públicas, cómo el laboral, que encuentra su principal fuente en el estatuto de los trabajadores y en los convenios colectivos concretos. Aunque, en lo que se refiere al acceso, derecho de sindicación e imparcialidad, el mandato constitucional no distingue entre funcionarios y laborales, por lo que su vinculación a dichos objetivos tendrá la misma intensidad en atención a que ambos colectivos conforman la función pública.

A pesar de ello, los distintos intentos de elaborar el estatuto a que se refiere este precepto constitucional no han distinguido entre una y otra clase de personal. El último borrador se titula estatuto básico del empleado público, quizás en una vuelta de tuerca más al proceso de laboralización de la función pública de los últimos años.

\section{DERECHOS Y DEBERES DEL PERSONAL AL SERVICIO DE LA FUNCIÓN PÚBLICA: LA FUNCIÓN PÚBLICA COMO SISTEMA}

El derecho de la función pública ha adquirido entre nosotros una notable expansión y extensión como consecuencia de la tendencia reguladora que inspira la actuación de las diferentes Administraciones públicas en relación con el personal. Regulación de la jornada laboral, del régimen de los representantes del personal o de la formación continua, son otras tantas manifestaciones de la preocupación de los Gobiernos por contar con un personal bien preparado y plenamente en sintonía con los objetivos constitucionales.

La función pública o, cómo algunos dicen ahora, el empleo público, necesita de unas reglas generales, de un estatuto que permita disponer de una única norma jurídica en la que desarrollar las previsiones del párrafo tercero del artículo 103 de la Constitución: derechos, deberes, acceso, sindicación, incompatibilidades, garantías para la imparcialidad...

¿Derecho de la función pública o derecho del empleo público? A los efectos de una intervención oral no puedo entrar en este tema a fondo. Baste ahora señalar que intentar eliminar la diferencia entre funcionarios y laborales re- 
quiere reformar la Constitución pues pienso que cuándo el constituyente se refiere a los funcionarios en el artículo 103 se está refiriendo, al menos, a la concepción amplia de funcionario que, como es sabido, recoge los aspectos esenciales de su régimen, sobre todo el que se refiere al de la estabilidad. Por otra parte, siempre es posible deslindar la actividad propia de los sujetos que la realizan. Desde ese punto de vista, claro que se puede distinguir el derecho de la actividad de función pública y el derecho que regula el estatuto general del personal que realiza la función pública. $\mathrm{O}$, si se quiere, se puede hablar de derecho subjetivo de la función pública. En todo caso, se puede tratar de derecho de la función pública o derecho del personal al servicio de las Administraciones públicas.

En fin, se trate de derecho de la función pública o del empleo público, o de ambos a la vez, lo que interesa señalar en este momento es que, cómo suele ocurrir en general, podemos distinguir un concepto amplio y otro estricto de derecho, pongamos que de derecho subjetivo de la función pública, expresión que, al menos para mí, es más propia del Derecho Administrativo.

En sentido amplio, nos hallamos ante un conjunto de normas que regulan los derechos y deberes de las personas que prestan sus servicios en las Administraciones públicas, de las personas, seamos más claros, que trabajan en las Administraciones públicos. El servicio profesional de estas personas es un trabajo profesional como otro cualquiera aunque, eso sí, con unas notas características que lo singularizan puesto que es un trabajo profesional que se refiere al servicio objetivo al interés general. En fin, la perspectiva amplia contempla el universo de estas normas en general, sin orden ni concierto, sin una lógica que permita el establecimiento de un sistema. En sentido estricto, este conjunto de normas adquiere una determinada lógica que le permite adquirir una cierta unidad interna a partir del elemento central: la relación de servicio.

Este es el concepto medular, la relación de servicio que, de acuerdo con los principios constitucionales de aplicación, ha de ser una relación de servicio objetivo al interés general.

De nuevo, nos encontramos, también en esta materia, con una aproximación funcionalista al Derecho Administrativo, para la que, en efecto, el nervio central es la propia actividad administrativa, en esta ocasión caracterizada por su referencia a la relación de servicio objetivo al interés general. En esta perspectiva debe entenderse, a mi juicio, este sistema. 
Por ello, el derecho de la función pública es, sobre todo y ante todo, no únicamente el derecho de los sujetos que trabajan para la Administración pública, sino el derecho de la relación de servicio objetivo al interés general. Y, en el marco de esa relación de servicio objetivo al interés general, nos encontramos con determinados aspectos que modulan los derechos, los deberes y las condiciones de trabajo de las personas al servicio de las Administraciones públicas.

La siguiente cuestión que debemos plantearnos, antes de entrar de lleno en el análisis de los deberes, se refiere a la calificación de esa relación de servicio que la doctrina comúnmente ha entendido cómo una manifestación de las relaciones especiales de sujeción, quizás para así poder explicar los poderes de que goza la Administración en relación con sus empleados. Es sabido que una de las notas esenciales a estas relaciones especiales de sujeción reside en la ubicación en la Administración de la determinación unilateral del conjunto de derechos y deberes del personal a su servicio, así como de las condiciones de trabajo. Es decir, la unilateralidad es una característica medular de estas relaciones especiales que, hoy por hoy, la verdad es que ha sido modulada por la realidad y por la proyección en el ámbito del Derecho Administrativo del denominado pensamiento abierto, plural, dinámico y complementario.

En otros términos, así como en Alemania se ha abandonado esta construcción teórica por incongruente con la realidad, también nosotros debemos pensar que los modelos teóricos que ya no sirven para explicar el régimen y funcionamiento de las instituciones en la cotidianeidad. Normalmente, es la propia realidad quien condiciona la emergencia de nuevas explicaciones.

En el caso de la función pública parece claro que la laboralización creciente y la necesidad de que la Administración abandone el pedestal de la unilateralidad están diseñando un nuevo sistema con unos contornos no siempre congruentes. Es, también, la consecuencia de superar una idea unilateral del interés público, para situarse en postulados más abiertos y complementarios. Pero, sobre todo, la clave de los cambios reside en ubicarse en el concepto de la relación de servicio objetivo al interés general. Desde esta perspectiva se puede entender la panoplia de problemas y cuestiones que hoy rondan al llamado derecho de la función pública.

Los deberes de los funcionarios, así como sus derechos y el marco general de las condiciones de trabajo, han de entenderse y explicarse, no tanto desde la unilateralidad cuánto desde el acuerdo y la idea de que el derecho de la 
función pública tiene por finalidad esencial asegurar el funcionamiento de los servicios públicos en sentido amplio.

Intentar construir una teoría de los deberes al margen de la realidad, sin tener presente que la clave de la Administración reside en el servicio objetivo al interés general, es una tarea condenada al fracaso. Quizás, por ello, el Derecho Administrativo sea el derecho de la función administrativa entendida precisamente como tarea de servicio objetivo al interés general. Así, el sentido de los deberes de los funcionarios han de explicarse desde este punto de vista: desde la concepción del servicio objetivo al interés general.

\section{SOBRE LOS DEBERES}

La teoría de los deberes parte, además de la legislación aplicable, de la deontología o Ética profesional puesto que el trabajo en la función pública también tiene determinadas consideraciones de orden moral a las que deben sujetarse los agentes públicos. En este sentido, además de los deberes clásicos a que se refieren las Normas sobre la materia, debe subrayarse que el plus de responsabilidad que gravita sobre el trabajo al servicio de las Administraciones, encierra una fuerte carga de dimensión ética. En efecto, el trabajo al servicio objetivo de los intereses generales implica una serie de características como imparcialidad, honestidad o integridad, entre otras. Del mismo modo, es menester señalar que el trabajo al servicio objetivo de los intereses generales conlleva una especial sensibilidad frente a los derechos y libertades ciudadanas, una apuesta por el bienestar integral de los ciudadanos y un deseo de hacer las cosas bien hechas porque los funcionarios estamos en contacto diario con los asuntos de todos, con los asuntos de la comunidad.

Por otra parte, una sociedad que sólo valora la consecución de objetivos, que sólo pondera el poder, el dinero y la notoriedad, es una sociedad en la que la idea de servicio tiene carácter peyorativo ya que lo que se lleva es el poder, el dinero o la fama y, sobre todo lo mensurable, lo cuantitativo, importando menos las dimensiones cualitativas o el trato con las personas. En este ambiente florecen, es lógico, determinadas versiones de la función pública que terminan por condenarla a lo residual, aunque sean muchos los que busquen en ella la estabilidad soñada. Hoy, el ambiente general desanima los proyectos profesionales en los que no se ejerzan grandes poderes o se ganen grandes sumas de dinero, algo que es incompatible con la dedicación a la función pública. 
Hoy estamos en una crisis del principio de jerarquía, también en el orden administrativo, en un momento en el que pareciera que sólo existieran derechos, reclamaciones y reivindicaciones. Además, desde la perspectiva de los deberes, lo relevante para algunos, es siempre despejar balones y colocar en el tejado ajeno la responsabilidad o la tarea que sea.

Es sabido que ni el Estatuto de Bravo Murillo de 1852 ni la Ley de bases de 1918 recogen un conjunto ordenado y concreto de derechos y deberes de los funcionarios. Habría que esperar a la Ley de 1964, parcialmente vigente, para orientarnos en la materia aunque sin la pretensión de sistematización que habrá de buscarse a través de una interpretación razonable del Ordenamiento jurídico en su conjunto, al no disponerse todavía del ansiado estatuto de la función pública.

Siendo como es el estatuto de la función pública, la ordenación de los derechos y los deberes de los funcionarios, éstos ocupan un lugar central en la ordenación jurídica del sistema de la función pública. Los deberes, desde este panorama, se nos presentan como aquellas cargas u obligaciones que la Administración pública, en el marco jurídico, puede imponer al personal a su servicio precisamente, valga la redundancia, más que a partir de una relación especial de sujeción, en virtud del servicio objetivo al interés general, verdadero título que distingue y caracteriza la funcionalidad del trabajo público.

Hoy por hoy, y mientras no se promulgue el esperado estatuto de la función pública, la principal fuente para el estudio de los deberes la encontramos en la Ley de 1964 de funcionarios civiles del Estado adaptada, como norma preconstitucional que es, a la Constitución y al resto del Ordenamiento jurídico. Esto es así porque dicha Ley es la única que, hasta el momento, establece un conjunto, más o menos ordenado, de deberes de los funcionarios. Dichos deberes, insisto, deben interpretarse en el marco constitucional vigente y a la luz del servicio objetivo al interés general, que se erige en el patrón fundamental de entendimiento de todos los deberes de los funcionarios.

La Constitución española de 1978, es menester recordarlo ahora, señala la jerarquía como un principio básico del conjunto de la Administración pública. Por tanto, sobre toda la teoría de los deberes, la jerarquía sobrevuela en aras precisamente del mejor entendimiento de la eficacia, también establecida en la Constitución entre los principios de aplicación a todas las Administraciones públicas. 
En la explicación de los deberes se proyecta también la metodología desde la que últimamente intento comprender el entero sistema del Derecho Administrativo y de la función pública: el pensamiento abierto, dinámico, plural y complementario. Los deberes no se pueden considerar como un aspecto aislado del ordenamiento de la función pública sino en permanente relación con los derechos y el conjunto de materias a las que se refiere esta rama del Derecho Administrativo.

Es sabido que durante bastante tiempo la doctrina de la relación especial de sujeción ha sido la piedra de toque sobre la que se ha construido la especial vinculación del personal administrativo respecto de la Administración pública, quizás partiendo de la importación mecánica y acrítica de una institución que ya parece haber quedado superada a juzgar por el prestigio de que goza hoy en Alemania, país del que se importó tiempo atrás.

Es cierto que desde el principio de jerarquía se entiende bien la existencia de un poder de supremacía de la Administración para ordenar con eficacia su funcionamiento, para poder servir con objetividad el interés general. Pero también es verdad que, junto a la necesaria garantía del interés general, los funcionarios, el personal en sentido amplio, deben cumplir su trabajo, como se ha recordado, a partir de las más elementales normas del código deontológico que configura la función pública, el trabajo al servicio objetivo del interés general.

Una cuestión bien relevante se refiere al marco desde el que situarse para explicar los deberes de los funcionarios. Esta cuestión se puede abordar fundamentalmente buscando una enumeración positiva de cuáles sean dichos deberes o, por el contrario, desde la deducción, a partir de las normas punitivas que sancionan determinadas conductas de los funcionarios. Es decir, podemos trabajar directamente desde el elenco de los deberes $o$, indirectamente, desde la perspectiva de la sanción de los incumplimientos de las obligaciones del personal al servicio de las Administraciones públicas.

La Ley 30/1984 o la 23/1988 no nos proporcionan listado alguno de deberes. Sí, sin embargo, el artículo 31 de la Ley 30/1984, trata, al tipificar las faltas muy graves, de las obligaciones y deberes de los funcionarios en materia de responsabilidad disciplinaria. Es decir, este precepto, desde la perspectiva indirecta, debe entenderse completado por el Reglamento disciplinario de los funcionarios en la Administración del Estado a través de la tipificación de faltas graves y muy graves (Real Decreto 33/1986, de 10 de enero). 
En cambio, como hemos adelantado, el capítulo VII de la Ley de 1964 se refiere a "deberes e incompatibilidades", regulación que, dada la ausencia de regulación en la materia, constituye, en el marco constitucional, la principal fuente de la materia objeto de estudio de este trabajo. En dicho capítulo encontramos una definición expresa de los deberes que ha de completarse, según lo comentado, con las obligaciones que se deducen al establecer las faltas disciplinarias de los funcionarios públicos.

El capítulo VII tiene dos secciones. La primera, artículos 76 a 81, se refiere a los deberes de los funcionarios, regulación que está vigente, siempre desde la luz constitucional, al no haberse derogado ni por la Ley 30/1984 ni por la Ley 23/1988. La segunda, artículos 82 a 86 está dedicada a las incompatibilidades, hoy derogada por la Ley 53/1984 de 26 de noviembre.

Los deberes diseñados en la legislación citada deben completarse con los que son propios de las normas deontológicas de la función pública que, como todo trabajo humano, ha de atender a la consideración ética exigible a cualquier trabajo profesional. Es decir, desde la Constitución y la Ética del servicio público, podemos señalar que existe un deber de servicio objetivo al interés como deber central de obligado cumplimiento para todo el personal al servicio de la Administración pública, del que se derivan deberes como el de imparcialidad, dedicación al interés general, integridad, honestidad, austeridad ...

\section{ACATAMIENTO A LA CONSTITUCIÓN}

El acatamiento de la Constitución, más que un deber de los funcionarios públicos, constituye un requisito para adquirir la condición de empleado público. Suele citarse entre los deberes de los funcionarios porque el contenido mismo del acto de acatamiento de la Constitución implica la realización del quehacer público asignado de acuerdo con nuestra Carta magna, lo cual ofrece una determinada dimensión de deber pues se trata de acomodar el trabajo al servicio de la Administración pública de acuerdo con los principios y valores constitucionales.

El artículo 76 de la Ley de 1964 debe leerse, es claro, desde este punto de vista. Entonces, hasta podría afirmarse que del acatamiento a la Constitución derivan toda una serie de deberes genéricos que encuentran su justificación en la letra de la Constitución y muy especialmente en el precepto fundamental desde el que hay que entender el régimen de la función pública como sistema: la Administración pública sirve con objetividad el interés general. Aquí 
radica el centro del que dimanan el conjunto de deberes del personal al servicio de la Administración pública o, si se quiere, aquí se encuentra el principio que permitirá iluminar adecuadamente el alcance constitucional del deber del que se trate en cada caso.

El acatamiento a la Constitución constituye, desde el punto de vista normativo, la fuente de los deberes de los empleados públicos. Por ello, la cuestión relativa al problema que puede plantear un funcionario que jura o promete la Constitución formalmente pero no se encuentra personalmente vinculado por sus dictados ofrece un panorama bien complejo. Por una parte, es verdad que para ser funcionario es menester el acatamiento a la Constitución y que dicho acto de jura o promesa implica el cumplimiento del trabajo administrativo en el marco de la Norma fundamental. Y, por otra, también es posible que un funcionario no comparta los principios constitucionales o piense que deban ser reformados. Sin embargo, siendo esto así, también lo es que la Constitución vincula a los ciudadanos y a los poderes públicos, por lo que parece que el tenor del artículo 9.1 aclara el problema.

Ciertamente la historia del juramento está vinculada a la necesidad de garantizar determinadas lealtades, bien fuera para asuntos públicos o para negocios privados. Como es sabido, cuándo empieza a conformarse el Estado moderno y los parlamentos comienzan su andadura, el poder ejecutivo, el Rey, intenta asegurarse la fidelidad de los funcionarios a través de la fórmula del juramento que se efectúa al ser nombrado para el oficio público de que se tratara y que, con variaciones y transformaciones ha llegado hasta nosotros, si bien, evidentemente, con el sentido del cumplimiento de los valores y criterios democráticos que componen las Constituciones modernas, no con la finalidad de guardar fidelidad a la persona del Rey.

La pregunta de por qué el juramento o promesa de acatar la Constitución puede contestarse fácilmente haciendo referencia a que el trabajo al servicio de las Administraciones públicas, en la medida en que supone o implica tareas comprometidas con el bienestar general e integral de la ciudadanía, requiere de un plus de responsabilidad en el que se incardina la solemnidad, mayor o menor según los casos, de la promesa o el juramento.

Cuándo se contempla el sistema de la función pública desde la perspectiva de la relación especial de sujeción, tal y como hace el Tribunal Constitucional, entonces, como se lee en la sentencia de 8 de noviembre de 1993, parece obvio que tal vínculo justifique que el desempeño de la función pública vaya precedido de una declaración formal de acatamiento a la Constitución. 
Ahora bien, el mismo argumento, si basamos el modelo en el artículo 103.1, se puede esgrimir si es que concebimos los cimientos del sistema de función pública a partir del servicio objetivo al interés general.

Para terminar la glosa de este deber, debe señalarse que, en efecto, si bien se trata de una obligación formal e inicial, como ya queda argumentado, su contenido se proyecta en el tiempo, de forma y manera que el funcionario está obligado a que su quehacer administrativo esté presidido en todo momento por los principios y preceptos de la Constitución.

\section{OBEDIENCIA Y COLABORACIÓN}

El principio de eficacia es un principio con rango constitucional, al igual que el de jerarquía (artículo $103 \mathrm{CE}$ ). En virtud del primero, la Administración ha de poder organizarse de manera que cumpla sus objetivos $y$, para ello, a partir del segundo, se estructura internamente de manera que existe una cadena de mando con superiores e inferiores, escrito sea sin ánimo peyorativo.

La Administración pública es una estructura organizativa jerárquica, lo que, en los tiempos que corren, aunque pueda llamar la atención, responde a la necesidad, en efecto, de que se pueda asegurar un "mínimum" de servicio objetivo al interés general como parámetro ordinario de su entera actividad.

Por otra parte, la colaboración es igualmente un deber del personal al servicio de las Administraciones públicas puesto que, aunque se deduzca del artículo 76 de la Ley de 1964, resulta que es exigible éticamente de un trabajo que se realiza al servicio de la comunidad. De ahí que la colaboración sea una consecuencia de la fuerza de la ética del servicio público, de la misma manera que, desde este punto de vista, la jerarquía no debe degenerar en autoritarismo o en ejercicio irracional y desproporcionado del poder, como algunas veces acontece.

La Administración pública, como el Ejército y la Iglesia, son instituciones jerárquicas por esencia pues tienen, las tres, bien claros su objetivos que, son de tal trascendencia que requieren de la garantía del cumplimiento de sus fines, lo cuál sólo puede lograrse, de acuerdos a sus respectivas naturalezas, desde la instauración de una razonable jerarquía, a la que acompaña una también razonable obediencia. 
El superior jerárquico tiene mando en la Administración y goza de potestades de dirección precisamente para asegurar mayores cotas de interés general en el trabajo de la unidad administrativa a su cargo. En este sentido, la jerarquía, por obvias razones, debe reforzar la neutralidad, objetividad e imparcialidad de las decisiones. Es más. la jerarquía es un principio que sólo se aplica en cuánto a la consecución de los fines de interés público asignados a la unidad u órgano administrativo de que se trate. El mando, pues, se ejerce al servicio objetivo del interés general. Cuándo ello no ocurre, entonces aparece el proceloso mundo de la corrupción con toda su panoplia de manifestaciones: mobbing, abuso de poder, enriquecimiento personal, tráfico de influencias, uso de información privilegiada...

El deber de obediencia, es consecuencia del principio de jerarquía: el superior jerárquico manda y el inferior obedece; está regulado en el artículo 79 de la Ley de 1964 en estos términos: " los funcionarios deben respeto y obediencia a los superiores jerárquicos, acatar sus órdenes con exacta disciplina, tratar con corrección al público y a los funcionarios subordinados y facilitar a éstos el cumplimiento de sus obligaciones".

Seguramente, si hoy se diera nueva redacción al deber de obediencia se utilizarían otros términos distintos, más en consonancia con los tiempos, aunque probablemente establecería los mismos principios, que son universales y atemporales.

En efecto, la eficacia requiere de obediencia a las órdenes del superior jerárquico pues, de lo contrario, estaríamos en un ambiente de indisciplina en el que no se alcanzarían los objetivos propuestos con el consiguiente despilfarro derivado de tal proceder. Los que mandan ejercen potestades de dirección que se materializan a través de órdenes o indicaciones impartidas a los funcionarios subordinados, quienes las han de cumplir en sus términos siempre que estén incardinadas en el marco de los intereses generales a los que sirve la unidad administrativa de que se trate en cada caso.

Bien es verdad que por parte de los que mandan es exigible un comportamiento impecable en relación con los mandados, lo cuál no es fácil porque no pocas veces quien manda, o no tiene el talento preciso para mandar, o confunde la idea del mando con la idea de la sumisión o del sometimiento, ya felizmente superada, al menos teóricamente. Los directivos deben facilitar el cumplimiento de los deberes del personal, lo cuál implica que el ejercicio del mando, que es un arte y una ciencia también, sea una tarea sumamente difícil en una Administración democrática y que requiera una singular preparación 
y continua formación para que a través del poder la ciudadanía vea cada vez con mayor claridad una efectiva mejora de las condiciones de vida de las personas como consecuencia primera de la actuación administrativa.

Por ejemplo, a mí siempre me ha escandalizado, y no poco, que a veces el derecho al trabajo que toda persona tiene pueda ser negado a algunos funcionarios por muy diversas causas, en ocasiones, hasta de naturaleza ideológica. Nunca entendí bien, a pesar de haber estado ejerciendo funciones de dirección en la Administración pública cerca de quince años, que el derecho al trabajo de los funcionarios pudiera estar condicionado por el mayor o menor interés que pudiera tener el directivo en que determinada persona tuviera más o menos papel que despachar. Quizás sean resabios de versiones patrimoniales y subjetivas del ejercicio del poder que todavía pululan por algunas oficinas públicas, pero lo cierto es que, más o menos, se siguen produciendo situaciones, menos que más, desde las que se perpetran auténticos atentados a los derechos a la dignidad o la integridad moral de muchos empleados públicos.

Por otra parte, quien conozca bien hoy la Administración sabrá que hay más jefes que indios, por utilizar una expresión coloquial. Esto, que es así, impide que la jerarquía pueda desplegar toda su virtualidad al servicio de los objetivos establecidos. Son, se dice, las consecuencias de la crisis de la jerarquía y de la moda de la cooperación horizontal o de la coordinación. Es probable, pero lo que si es cierto es que la Administración debe actuar al servicio objetivo del interés general y para lograrlo debe disponer de los medios razonables y de los poderes adecuados para que el bienestar general e integral de los ciudadanos sea una realidad en crecimiento.

Desde luego que es relevante la promoción profesional y la carrera administrativa. Por supuesto, solo faltaría. Pero ello no es óbice, ni mucho menos, para que decaiga la eficacia del servicio público. Carrera administrativa y eficacia son dos conceptos que se deben entender, en mi opinión, desde la complementariedad y la compatibilidad, no desde la oposición o la confrontación.

En esta materia es una cuestión clásica la de los límites del deber de obediencia o, si se quiere, si se deben cumplir las órdenes ilegales. Porque incumplir una orden puede desencadenar un expediente disciplinario $y$, por otra parte, cumplir una orden ilegal puede dar lugar a un expediente de responsabilidad penal. La solución en la teoría es bien clara, en estos casos procede la desobediencia porque prima el principio de legalidad. Desde otro punto de vista, hay quien defiende que la obediencia de las órdenes ilegítimas siempre se puede reparar desde la postulación procesal de la obediencia de- 
bida. Sin embargo, si una orden es ilegal, es ilegal, y si hace falta advertirlo por escrito o dejar constancia por escrito, es la mejor solución para evitar las consecuencias que se pueden derivar del contenido de una orden ilegal. Se trata pues, de una cuestión de límites, pues no siempre, a veces sí, se puede determinar el momento en el que una decisión se convierte en ilegítima hasta el punto de amparar la desobediencia.

Aunque no es objeto propio de esta intervención analizar el problema del acoso moral en el trabajo, me parece indicado señalar que el aumento, a veces alarmante del mobbing en la función pública, se puede deber a un entendimiento de la jerarquía desde el autoritarismo. Un poder que tiene miedo a la motivación, que aspira a la afirmación permanentemente, que sólo tiene ojos para la desconfianza, que aparta a los más competentes y ansía la búsqueda de objetivos extramuros del interés general, abre las puertas a la autoritarismo y, por ello, a una amplia panoplia de manifestaciones de abuso de poder o de uso de poder para fines personales en un sentido amplio y variado.

El deber de colaboración, obvio dónde los haya, bien se entiende si la conciencia de servicio a los ciudadanos está bien afincada en los funcionarios y cargos públicos. Porque cuándo el bien general e integral de los ciudadanos es el espejo en que se miran las decisiones públicas, entonces la colaboración o cooperación se produce a nivel orgánico y a nivel funcionarial. Cuándo, por el contrario, el ambiente laboral está enrarecido por las conspiraciones y la división en bandos o cuándo no se busca lo general sino lo particular o partidista, entonces la colaboración, sea institucional o personal, brillará por su ausencia.

El artículo 76 de la Ley de 1964 dispone que " los funcionarios vienen obligados a colaborar lealmente con sus jefes o compañeros, cooperando al mejoramiento de los servicios, y a la consecución de los fines de la unidad administrativa a la que estuvieran destinados".

La obligación de la colaboración con los jefes ha de ser leal. Es decir, se trata de tirar del mismo carro en lo que se refiere a la instauración de un ambiente de trabajo digno de la condición humana, a dedicarse a la tarea con rigor de acuerdo con las órdenes e instrucciones recibidas, a sugerir cambios, a ejercer la iniciativa; en definitiva, a trabajar conscientes de que se está en el mismo barco y de que el capitán debe mover el timón con la seguridad de que el resto de la tripulación está en sus puestos haciendo posible la maniobra propia de cada momento. Hoy la lealtad es otro término que quizás no encaje bien en una mentalidad que sólo busca la realización personal y profesional, 
el poder, el dinero y la notoriedad, contándose en muchos casos con episodios de deslealtad motivados, quizás, en la obsesión por el ascenso al precio que sea, llegando en ocasiones incluso al chantaje.

Lealtad es fidelidad a la palabra dada, y si uno ha jurado o prometido la Constitución y el resto del Ordenamiento jurídico bien sabe cuándo está colaborando con lealtad o cuándo está trabajando desde la egoísta perspectiva del personalismo, aguas abajo, por supuesto, del servicio objetivo a los intereses generales. La lealtad, según el precepto que ahora comentamos, se proyecta sobre el superior jerárquico y también sobre los compañeros, siendo esta dimensión quizás más difícil que la primera. Más difícil porque si bien el jefe manda en virtud de un poder normativamente atribuido, los compañeros no tienen potestad de mando sobre nosotros, por lo que formalmente la colaboración o cooperación podría ser más complicada de fundamentar. Sin embargo, para que el trabajo salga, y salga bien, es necesario que las unidades administrativas trabajen armónicamente, y para ello es imprescindible que reine la cooperación entre todos los funcionarios, sea cual sea la posición que ocupen en la maquinaria administrativa.

Es también obvio que sólo habrá cooperación si existe un buen ambiente laboral. Esta cuestión compete, aunque no sólo, pero si primariamente, a la cabeza de la organización. Se trata de un deber de quienes mandan que deben tener siempre presente pues una unidad administrativa dónde hay buen ambiente laboral, normalmente consigue los objetivos asignados. Y, en sentido contrario, dónde domina la división y el fraccionamiento, los asuntos o no salen o salen mal como lógica consecuencia de falta de condiciones favorables para el trabajo propio de la función pública.

La colaboración, sigue diciendo el precepto que estamos examinando, ha de hacerse para conseguir el mejoramiento de los servicios. Es bien claro que el mejoramiento de los servicios es una tarea de toda la unidad. Se consigue si reina el buen ambiente, si se analiza con frecuencia por qué sí o por qué no se alcanzan los objetivos propuestos en los plazos acordados. Cuándo los directivos piden sugerencias a todos los funcionarios de la unidad sobre como mejorar el servicio que se presta a la ciudadanía, ordinariamente se sorprenden gratamente de los comentarios del personal porque las personas que componen una determinada unidad saben perfectamente las carencias y las virtudes de esa organización. Lo difícil es motivar al personal para que se implique en la tarea, lo cuál no es difícil cuándo habitualmente el ambiente laboral está presidido por la colaboración leal. 
El objetivo de la colaboración leal, según el precepto que estamos comentando, es la mejora continua del servicio que se presta a los ciudadanos. Insisto, para que ello sea posible es imprescindible que se respire un ambiente grato y estimulante. De lo contrario, la mejora de los servicios es imposible; todo lo más podrán confeccionarse frías estadísticas con determinados resultados, pero nada más.

Junto a la mejora de los servicios, la colaboración leal también propicia el cumplimiento de los objetivos asignados a la unidad de que se trate. Es obvio que cada unidad ha de tener unos objetivos conocidos por todo el personal, sea cuál sea el lugar que ocupen en la estructura administrativa. Sin embargo, no por obvia implica que sea lo normal en la Administración este proceder. Podríamos preguntar al personal de numerosas unidades si conoce los objetivos que tienen asignados y nos podríamos llevar a una desagradable sorpresa. Los objetivos, los fines, deben definirse entre todos los miembros de la unidad atendiendo, claro está, a los superiores intereses generales a los que debe servir el centro directivo al que esté adscrito la unidad. Esos objetivos deben ser objeto de seguimiento periódico, de análisis para ir adoptando las decisiones que procedan en cada caso. Si no existe colaboración leal, los objetivos serán imposibles de alcanzar.

En materia de eficacia administrativa, pienso que debe llamarse la atención sobre el peligro de absolutizar los fines. Me refiero a esa tentación sutil de trascender los procedimientos administrativos, largos y pesados, para poder alcanzar los fines previstos. Además de que esta metodología desemboca ordinariamente en la corrupción, el desprecio por los procedimientos denota poca sensibilidad frente al principio de igualdad y de transparencia. Lo que habrá que hacer si se advierte que los procedimientos no son los adecuados, es reformarlos para que, a su través, se puedan adoptar decisiones de servicio objetivo al interés general. Quienes, por el contrario, piensan que lo único importante es conseguir los objetivos, se olvidan de que la Administración pública no es una empresa más; es, en todo caso, una empresa cuyos resultados han de medirse sustancialmente en función del servicio objetivo al interés general, que se desprende de sus decisiones y actuaciones.

Igualmente, absolutizar la jerarquía, ya lo hemos señalado, da lugar al autoritarismo, sorprendentemente cada vez más de moda entre nosotros, quizás por el predominio que se aprecia en las aspiraciones de no pocas personas al poder, al dinero y a la notoriedad. La necesidad de afirmación personal, de demostrar que se manda, que se tienen subordinados, que se dirige, ocasiona no pocas veces un ambiente de cierta distancia entre jefes y personal que sue- 
le distorsionar el ambiente laboral. A veces es posible, no siempre, que en ambientes autoritarios se consigan los objetivos a base de amedrentar y amenazar al personal con toda suerte de estrategias.

Las Administraciones suelen contar con unidades administrativas dedicadas a impulsarla mejora continua de los servicios. Lo que ocurre en algunos casos, es que estas unidades no disponen del rango necesario para acometer su tarea con racionalidad. En otros casos, su excesiva dependencia política impide que con autonomía se pueda realizar la tarea de racionalización y modernización necesaria para la mejora permanente.

También me parece que en el marco de la colaboración leal y la mejora de los servicios es buena cosa facilitar al personal que presenten las sugerencias e iniciativas que estimen por conveniente. Cuándo se fomenta este ambiente, también se puede apreciar la profesionalidad del personal también en este punto. La mejora de los servicios, sobre todo en el tiempo que nos ha tocado en suerte, está igualmente muy conectada con la apuesta por contribuir a una mayor humanización de la realidad. Primero porque el trabajo de servicio objetivo al interés general en ocasiones puede derivar en una fría y distante relación de la burocracia con los ciudadanos. Y segundo, porque no es infrecuente que en un mundo tan cosificado como en el que vivimos, sea relevante rescatar los valores y la fuerza del factor humano, que en la Administración pública tiene evidentes consecuencias en la construcción de una ética del servicio público comprometida con los derechos fundamentales de las personas, en especial de los desfavorecidos.

La mejora de los servicios implica decisiones sobre personal y medios materiales. Por eso, la colaboración leal reclama que cuando proceda se expresen y manifiesten las necesidades objetivas de orden material o de personal que permitan trabajar en un contexto de dignidad y normalidad exigible a las unidades de la Administración pública.

Por otra parte, el artículo 80 de la Ley de 1964, además de configurar como deber el sigilo profesional, diseña una modalidad de colaboración consistente en el esfuerzo en la mejora de las aptitudes profesionales y de la capacidad de trabajo. Se trata pues, de un deber personal del funcionario al que la organización administrativa debe prestar especial atención para facilitarlo y propiciarlo. Ello quiere decir, que los responsables deben tener muy presente esta cuestión para permitir que el personal sintonice con la filosofía de la formación continua y pueda acudir, cuándo sea necesario, a las acciones formativas que mejoren sus aptitudes profesionales y su capacidad de trabajo. 
Sin embargo, este deber que ha de ser facilitado por los responsables no sólo se refiere a facilitar el acceso a los cursos que verdaderamente mejoren las aptitudes profesionales y la capacidad de trabajo. En el puesto de trabajo también debe propiciarse el cumplimiento de este deber con acciones "ad hoc" de contenido formativo. En cualquier caso, es un deber personal y como tal ha de ser cada funcionario quien se esfuerce por la mejora de sus aptitudes profesionales y su capacidad de trabajo.

Los directivos en la Administración pública tienen una tarea difícil en este sentido. Para cumplirla con éxito han de comprometerse con lo que denomino mentalidad abierta, metodología del entendimiento y sensibilidad social. Han de pensar cotidianamente cómo ayudar al personal también en la mejora de sus aptitudes profesionales y en la mejora de la capacidad profesional. Se trata, por supuesto de una tarea personal, de cada quien, pero también es cierto que desde la dirección se puede, y se debe, facilitar.

Desde esta perspectiva será más fácil entender algo que me parece que está en la entraña democrática de la Administración pública: que en el corazón de los expedientes existen necesidades colectivas, intereses generales de ciudadanos que esperan una resolución justa y humana a la vez. Este es, me parece, el gran reto que tiene planteada hoy la Administración en las democracias pues, si no es consciente de su compromiso con los derechos fundamentales y las libertades públicas, una vez más el aparato burocrático seguirá mirándose a sí misma.

Ciertamente, el deber de colaboración parte del principio de buena fe que implica la predisposición del personal por sacar, digámoslo así, los intereses generales adelante, de acuerdo con los mandatos y parámetros constitucionales. En este sentido, este deber comprende también, es obvio, el buen trato a los ciudadanos. Este deber obliga a todos los miembros de la Administración pública, no sólo a quienes atienden una oficina de información al público. Tratar bien a los ciudadanos no es una mera consideración de contenido moral general sino que es la consecuencia lógica del papel central de los ciudadanos en relación con la Administración pública. Tratar bien a las personas que se acercan a las Administraciones públicas no es, insisto, una técnica, es una obligación ética en consonancia con el sentido y funcionalidad que tienen las personas y sus derechos en el entendimiento del interés general en el Estado social y democrático de Derecho. Nada más y nada menos.

Desde otro punto de vista, el incumplimiento del deber de colaboración nos sitúa ante un claro ilícito administrativo que puede ser considerado como 
una falta muy grave en caso de abandono del servicio o de notoria falta de rendimiento que implica inhibición en el cumplimiento de las tareas asignadas.

Como falta grave se tipifica, es lógico, la grave desconsideración con los administrados y con los superiores, compañeros o subordinados. El deber de colaboración, en fin, más que un deber susceptible de plantearse en el ámbito de la corrección disciplinaria, es un deber que presume una actitud general de trabajar al servicio objetivo del interés general

\section{DEBER DE RESIDENCIA}

Con el estudio del deber de residencia comenzamos el análisis, que será breve necesariamente, de los deberes inherentes al puesto de trabajo. Es lógico que se resida en el lugar dónde está ubicado el puesto de trabajo tal y cómo dispone el artículo 77 de la Ley de 1964.

Siendo esto así, no lo es menos que las normas deben interpretarse de manera razonable y congruente con la realidad social, que hoy nos enseña que muchos ciudadanos viven en ciudades dormitorios o en términos municipales colindantes con la gran capital en que trabajan, dándose el caso de que pueden tardar menos tiempo a la oficina que quienes viven en el mismo municipio de su puesto de funcionario.

Lo realmente importante es que el funcionario cumpla con dedicación y eficacia su trabajo y todas sus obligaciones, lo que no parece reñido con vivir en Majadahonda, San Sebastián de los Reyes, Parla o cualquier ciudad del entorno de Madrid, dónde existen trenes de cercanías que permiten llegar a la oficina antes que a una persona que se desplace en vehículo de una punta a otra de Madrid.

Por ello, quizás sea más apropiado ampliar el deber de residencia en el municipio a otro concepto jurídico o geográfico más acorde con la realidad. En este contexto, con cautela y sentido común habría que explorar, también en el ámbito de la función pública, las posibilidades del teletrabajo. Ordinariamente, será imprescindible la presencia en la oficina, pero según los casos y la naturaleza del trabajo a realizar, se podría pensar, con rigor y sentido de la responsabilidad, si algunos funcionarios podrían ser más eficaces si trabajaran en su domicilio pertrechados de los medios tecnológicos que necesiten para su tarea profesional. No pienso en una posibilidad generalizada, sino para algunos supuestos y en algunas secuencias temporales. Indiscutiblemente, si esta opción fuera posible, debería estar bien motivada y, de dar malos resultados, abortada. 


\section{CUMPLIMIENTO DE LA JORNADA}

Consecuencia del derecho y deber de trabajar es cumplir con una jornada temporal que permita ejercer dicho derecho-deber. El artículo 78 de la Ley de 1964 dispone en este sentido que la jornada de trabajo de los funcionarios será la que reglamentariamente se determine.

Para la Administración del Estado, el órgano que tiene atribuida la competencia por delegación del ministro del ramo es el secretario de Estado de Administración pública, a través de la famosa instrucción de jornada, en la que se establece, oídos los representantes del personal, el calendario laboral: el instrumento técnico por el que se establece la distribución de la jornada y la fijación de los horarios que debe ser aprobada antes del 28 de febrero de cada año previa, negociación, con las organizaciones firmantes del acuerdo de 13 de noviembre de 1992.

Con independencia de si es razonable en un sistema abierto como el nuestro que se limite la capacidad de negociación a las organizaciones firmantes de un acuerdo con la Administración, lo cierto y verdad es que la norma establece que los horarios se acomodarán a las necesidades del servicio, para facilitar la atención a los ciudadanos, que se podrá establecer una pausa de treinta y minutos que computa como trabajo efectivo, que la distribución anual de la jornada no podrá alterar el número de vacaciones que senale la normativa en vigor y que dichos horarios deben difundirse convenientemente.

En una intervención de esta naturaleza, más que entrar en los diferentes regímenes de horarios posibles, que ciertamente son más de uno, y de dos, y que últimamente se han dado pasos razonables para adecuar los horarios a las personas, no podemos detenernos mucho tiempo en este punto, variable dónde los haya.

En todo caso, me gustaría apuntar que los horarios deben adecuarse al servicio, a la naturaleza del servicio público que se presta, lo cuál significa que se va a tener presente a los ciudadanos usuarios de dicho servicio de interés general. Pero también es importante contar con horarios razonables, humanos, adecuados a la realidad y que, en la medida de lo posible, tengan en cuenta la conciliación de la vida familiar y profesional, lo cual me parece relevante para el libre desarrollo de las personas. 


\section{SIGILO Y SECRETO PROFESIONAL}

En los códigos éticos y deontológicos profesionales suele citarse la obligación del silencio de oficio cómo expresión de la discreción que ha de caracterizar el trabajo de los profesionales. Es un deber que se denomina deber de sigilo (SÁNCHEZ MORÓN) en la función pública y que consiste en el deber de no revelar determinados conocimientos de los que se dispongan por razón del cargo y que no se refieran al bienestar general de los ciudadanos.

En la historia de la burocracia, como nos cuenta SÁNCHEZ MORÓN, el secreto era fundamental porque el sistema estaba montado sobre el secreto del cargo en la medida en que del monopolio de las informaciones públicas se derivaba un gran poder celosamente guardado mediante la imposición de grandes sanciones a su incumplimiento. Frente al deber de sigilo, es necesario distinguir el deber de secreto, que impide al funcionario revelar las informaciones o datos que conozca o posea por razón de su cargo y que estén cubiertas por una declaración legal de secreto oficial.

Para otros autores, es menester diferenciar el deber genérico del deber específico de secreto. El general se predicaría de todo funcionario por el hecho de serlo y con respecto a cualquier materia a la que pueda tener acceso por su condición de funcionario. Su protección la encontramos en el artículo $7 \mathrm{j}$ ) del Reglamento disciplinario de los funcionarios de la Administración del Estado. El deber específico sería el que le corresponde en concreto de acuerdo con el puesto de trabajo que esté desempeñando, en función de su contenido específico (GARCÍA-TREVIJANO).

Ciertamente, el trabajo al servicio objetivo del interés general da lugar al conocimiento de hechos y circunstancias que reveladas podrían dejar desprotegido precisamente el interés público. Por eso, es lógico que exista un deber de silencio de oficio, si se quiere de discreción profesional. Ahora bien, frente a la perspectiva tecnocrática del secreto, es necesario señalar que los conocimientos e informaciones públicas de las que se disponga por razón del cargo deben ser utilizadas únicamente para la mejor gestión del interés público. Es decir, atrincherarse en el monopolio de determinadas informaciones, traficar con ellas dentro de la propia organización pública para conservar o mejorar la propia posición constituye una práctica maquiavélica que impediría atender con dedicación y lealtad los asuntos públicos con la libertad y responsabilidad requerida. 
Evidentemente, cuándo existen declaraciones formales por la que un funcionario adquiere un compromiso específico de silencio, nos encontramos en el ámbito del secreto oficial. En estos casos, los incumplimientos son más fáciles de conocer y las sanciones más contundentes por obvias razones.

En las democracias, como ya hemos señalado, las instituciones públicas son de la gente, y la gente debe poder conocer su funcionamiento y las razones del ejercicio de las potestades públicas. Ahora bien, todo ello es compatible con la discreción de los funcionarios en lo que se refiere al conocimiento de hechos e informaciones que, en poder de los particulares, podría romper el principio de igualdad ante, por ejemplo, la publicidad o concurrencia en las contrataciones públicas. Es decir, la información privilegiada, verdadera corrupción y delito hoy ubicado en el Código penal, es un cáncer que debe extirparse pues quiebra la transparencia e introduce el amiguismo, el clientelismo y cualesquiera de las más execrables formas de corrupción.

En términos generales, podría entenderse que existe una protección penal de la información adquirida como consecuencia del ejercicio de funciones públicas en el delito de violación de secretos a que alude el artículo 417.1 del Código Penal. La protección es más clara cuándo la violación del deber está cubierta por una especial declaración formal en ese sentido. Se trataría del caso del funcionario que tras haberse comprometido por escrito de no revelar información alguna sobre el centro para el seguimiento de crisis de presidencia del gobierno, pone a disposición de determinados periodistas ciertas informaciones sobre el funcionamiento interno de esa dependencia administrativa.

En esta materia suele ser habitual traer a colación el problema de la presencia de un funcionario como testigo en un juicio en el que se le reclama que comunique al órgano judicial determinada información que conoce por razón de su cargo. En estos supuestos se arbitran dos medidas.

La primera consiste en la aplicación del artículo 1247 del Código Civil en cuya virtud son inhábiles para la prueba de testigos quienes están obligados a guardar secreto, por su estado o profesión, en los asuntos relativos precisamente a estas cuestiones. De acuerdo, pues, con una interpretación literal del precepto, no podrían ser obligados a declarar como testigos.

La segunda trae causa del artículo 425 de la Ley de Enjuiciamiento Criminal, a cuyo tenor, cuándo un funcionario no pudiera declarar sin violar el 
secreto que por razón de su cargo estuviere obligados a guardar o cuándo procediendo en virtud de obediencia debida no fueran autorizados por su superior jerárquico, podrá declarar otro funcionario por sustitución autorizado por el superior jerárquico. Está fórmula plantea graves interrogantes pues no parece razonable que la obediencia debida tenga el alcance ilimitado que parece deducirse del precepto.

El deber de secreto tiene especial relevancia cuándo se adquiere en virtud de la Ley de secretos oficiales. Este deber en un Estado democrático tiene una funcionalidad excepcional, mientras que en un Estado autoritario está a la orden del día. Por tanto, cuándo se apela desproporcionadamente al interés público para no dar a conocer determinadas informaciones y cuándo se esgrime frecuentemente este deber, podemos pensar razonablemente que estamos ante un Estado policial.

El deber de silencio profesional puede también analizarse desde la perspectiva de la libertad de expresión de los funcionarios. Es decir, de acuerdo con la tesis tradicional, la relación especial de sujeción modula el régimen general del ejercicio de los derechos de quienes tienen la condición de empleados públicos, pudiéndose imponer ciertos límites.

La doctrina entiende mayoritariamente que las relaciones especiales de sujeción no pueden limitar derechos fundamentales. El Tribunal Constitucional, sin embargo, parece seguir la posición contraria. Pues bien, en mi opinión, como ya he señalado, la clave se encuentra, no en la relación especial de sujeción, sino en la relación de servicio objetivo al interés general, en cuya virtud es posible que el contenido del derecho a la libertad de expresión pueda ser modulado precisamente en atención al servicio objetivo al interés general al que se deben los empleados públicos. Por tanto, se puede llegara afirmar que para quienes se encuentran en la función pública, su derecho a la libertad de expresión debe entenderse precisamente en el marco del servicio objetivo al interés general.

\section{LOS DEBERES EN EL INFORME DE LA COMISIÓN DE EXPER- TOS PARA EL ESTUDIO Y PREPARACIÓN DEL ESTATUTO BÁSICO DEL EMPLEADO PUBLICO}

Es sabido que la Comisión de expertos entregó su dictamen el 25 de abril de 2005 y que en el trabajo presentado encontramos en el apartado XVI la siguiente rúbrica "Código ético y deberes de los empleados públicos". Dicho 
epígrafe plantea la cuestión de los deberes desde la perspectiva de la ética, lo que me parece acertado y adecuado a la propia naturaleza de la existencia y justificación constitucional de los deberes mismos. A continuación se enuncia la siguiente proposición en el punto 95 del dictamen: "El fundamento ético de los deberes de los empleados públicos y la conveniencia de establecer un listado sistemático de deberes en el estatuto".

Para los expertos, nos encontramos ante una buena ocasión para establecer un listado de deberes y terminar así con esa situación de relativa indefinición que se deriva de la existencia de normas dispersas y del esfuerzo de doctrina y jurisprudencia por ir induciendo el conjunto de los deberes y obligaciones de los empleados públicos. Es verdad, como también señalan los autores del dictamen, que probablemente la ausencia de ese catálogo de deberes ha permitido pensar más desde la garantía, desde la tutela de la posición jurídica individual del empleado público, que desde la perspectiva de las obligaciones y deberes inherentes a quien trabaja al servicio objetivo del interés general. De todas formas, debemos operar desde el equilibrio entre ambas posiciones para evitar planteamientos desenfocados que den lugar a regulaciones descompensadas hacia una parte o hacia la otra.

A renglón seguido, los autores del informe constatan la existencia de varios Códigos de ética y conducta de empleados públicos en algunos Estados y Organizaciones Internacionales, con contenidos análogos pero consecuencias jurídicas bien dispares en muchos casos. La OCDE y el Consejo de Europa han impulsado muchos de estos Códigos desde la necesidad de fortalecer la institucionalidad y recuperar la confianza perdida entre ciudadanos y gobiernos.

En mi opinión, lo he argumentado en mis publicaciones sobre ética pública, la existencia de estos Códigos al menos sirve para difundir los valores del servicio público en la sociedad y entre los ciudadanos y así colaborar al respeto y prestigio del trabajo al servicio objetivo del interés general. Otra cosa bien distinta es si a muchos Códigos, mucha ética o viceversa. La cuestión no es baladí y enlaza con una curiosa doctrina que todavía sigue proponiendo que la sola promulgación de la ley o la publicación de un reglamento transforman inevitablemente la realidad y la conducta de los ciudadanos. A quienes patrocinan estas taumatúrgicas versiones de la actividad de legislación en sentido amplio habría que decirles que es menester para que ello se produzca una no pequeña educación cívica y una Administración bien preparada para ejecutar razonable y sensatamente el contenido de las leyes. 
Como recuerdan los redactores del dictamen, estos Códigos suelen responder a la idea de "buena administración" como derecho fundamental de los ciudadanos tal y como la configura el proyecto de Tratado por el que se instituye una Constitución para Europa. Ahora bien, derecho en garantía de sus intereses legítimos en sus relaciones con las Administraciones públicas. También se traen a colación los últimos acuerdos del Consejo de Ministros por el que se aprobaron los Códigos de buen gobierno para los miembros del gobierno y se ordena al Ministerio de Economía elaborar unas buenas prácticas para las empresas públicas y al de Administraciones Públicas el Código de conducta para los empleados públicos involucrados en la contratación.

Es verdad que mientras algunos países han elaborado Códigos éticos elaborando un catálogo de deberes deontológicos, España y los países de Derecho Administrativo continental han seguido la tradición de la regulación legal de los deberes y obligaciones de los empleados públicos. Desde esta perspectiva, los redactores del informe entienden que el listado de los deberes debe inspirarse en los principios de ética y conducta "aparte de otras exigencias funcionales". Parece ser, además, que existe una amplia coincidencia entre los interlocutores de la Comisión de Expertos sobre la aplicación de los deberes a todo el conjunto de la función pública, sin distinguir personal funcionario de personal laboral. Los mismos redactores del informe entienden que los deberes han de ser los mismos, conclusión que compartiría siempre que dichos deberes se deriven del servicio objetivo al interés general, punto central que aúna a funcionarios y laborales que trabajan en el sector público.

A partir de estas consideraciones, la Comisión de expertos procede a identificar cuáles son los principios de conducta de los empleados públicos que deben tenerse en cuenta y aplicarse en la actualidad. A partir de ellos, los autores del informe entienden que podrá deducirse la tipificación de las conductas sancionables, en un proceso inverso al seguido hasta el momento. Cómo es lógico, los autores del dictamen señalan que el listado de los principios puede ser desarrollado con normas de conducta más específicas y detalladas, sin perjuicio de la obligación, dicen, de cumplir tales deberes de buena fe aún cuando el incumplimiento carezca de trascendencia disciplinaria, lo que no será fácil salvo que exista una fuerte auto-conciencia de servicio público y una elevada educación cívica.

¿Cuáles son, pues, los principios de ética y conducta a tener en cuenta según los expertos? Los siguientes: protección del interés público de acuerdo con el Ordenamiento jurídico, lealtad institucional, imparcialidad y objetividad, integridad, honestidad y ejemplaridad, austeridad, profesionalidad, ini- 
ciativa, diligencia y receptividad, responsabilidad y transparencia, así como la confidencialidad, cuándo proceda. A partir de estos principios se establecen los siguientes deberes:

- Respetar la Constitución, los Estatutos de Autonomía y el resto del Ordenamiento jurídico.

- Imparcialidad en el ejercicio de sus funciones y servicio objetivo a los intereses generales.

- Promoción del respeto a la igualdad entre hombres y mujeres en el servicio público.

- Obediencia a la instrucciones y órdenes de los superiores, salvo cuándo se trate de órdenes manifiestamente ilegales.

- Cumplimiento con diligencia las tareas que legalmente les correspondan o se les encomienden, y, en su caso, resolver dentro de plazo los procedimientos o expedientes de su competencia.

- Colaboración con los superiores y compañeros.

- Cumplimiento de la jornada y el horario establecido.

- Guardar secreto de aquellas informaciones que tengan dicho carácter según la legislación en vigor.

- Discreción en relación con aquellos asuntos que conozcan por razón de su cargo, sin que puedan hacer uso de la información obtenida para beneficio propio o de terceros, o en perjuicio del interés público.

- Información a los ciudadanos sobre todas aquellas materias en asuntos que tengan derecho a conocer, así como para facilitarles el ejercicio de sus derechos y el cumplimiento de sus obligaciones.

- Tratar con atención y respeto a los ciudadanos y a sus superiores, compañeros y subordinados.

- No contraer obligaciones económicas o de otro tipo con personas o entidades que puedan desviarle del cumplimiento de sus deberes. 
- Declarar cualquier interés público relacionado con el ejercicio de sus funciones, aunque no entrañe un conflicto de intereses.

- Abstenerse en aquellos asuntos en que tenga un interés personal conforme a la legislación vigente.

- No utilizar los recursos y bienes de la Administración en provecho propio de de personas allegadas y deber de velar por su conservación.

- Formación profesional en los términos que se establezcan.

- Observar las normas de seguridad y salud laboral.

Es bien relevante el intento de sistematizar el conjunto de los deberes del personal al servicio de las Administraciones públicas pues, como se ha recordado en distintos momentos de la intervención, era una tarea pendiente que ahora se emprende, al menos desde los comentarios de los expertos. Se parte, pues, de una serie de principios desde los que se deducen el elenco de deberes.

Sobre el principio de la protección del interés público de acuerdo con el Ordenamiento jurídico debo señalar que estando de acuerdo en lo fundamental, como no podía ser de otra manera, pienso que, si somos congruentes con el artículo 103.1 de la Constitución habríamos de escribir algo así como el principio del servicio objetivo al interés general de acuerdo con la Ley el Derecho, pues la expresión Ordenamiento jurídico podría ser interpretada desde el positivismo cerrado y excluir algunas fuentes del Derecho que, en mi opinión, constituyen la expresión del respeto a la dignidad de la persona y los derechos fundamentales como son los principios generales del Derecho.

En relación con la lealtad constitucional, bienvenida sea porque lo que aquí se propone no es más que la recepción en el estatuto de algunos de los principios medulares de la reforma de la Ley 30/1992 operada en 1999, entre los que, por cierto, estaba el principio de lealtad institucional, principio que plantea la necesidad de la lealtad del personal a los objetivos institucionales de la organización, lo que, obviamente excluye las perspectivas parciales y obligará a los Administraciones públicas a elaborar con mayor participación los objetivos de la institución, que habrán de ser revisados periódicamente.

La imparcialidad y la objetividad son dos principios con relevancia constitucional que aparecen expresamente previstos en el artículo 103 de la Constitución. 
La inclusión de la integridad y la honestidad se refieren a características esenciales que han de acompañar y distinguir al personal al servicio de las Administraciones públicas en la medida en que su trabajo ha de estar orientado hacia lo público, evitando utilizar el cargo o la función para el beneficio personal, familiar o de grupo.

La ejemplaridad, muy bien traída como principio, expresa el convencimiento de que la gestión pública conlleva un plus de responsabilidad por cuanto el trabajo en el sector público, sea cual sea el lugar que se ocupe en la maquinaria administrativa, supone el manejo de lo común, de lo de todos, que obviamente incorpora una mayor exigencia que la administración particular. Además, en la organización, si quienes mandan son ejemplares, es más fácil que todos cumplan sus deberes con mayor dedicación e ilusión.

La austeridad reclama de quienes administran fondos y recursos públicos que sean conscientes de que son escasos y de que son de la comunidad. A veces, precisamente la condición impersonal de esos fondos facilita que se manejen de forma irresponsable y demasiado alegre.

La profesionalidad también se predica, claro está, de la función pública pues es un trabajo profesional como otro cualquiera y, por tanto, debe realizarse bien atendiendo a sus propias singularidades. Además, trabajar para el conjunto de los ciudadanos hasta pareciera que debiera implicar un mayor esfuerzo por hacer bien el trabajo en sus más pequeños detalles.

El sentido de la iniciativa es un deber que expresa la necesidad de que el personal asuma su tarea desde una perspectiva dinámica. Es decir, cada empleado debe pensar periódicamente cómo puede hacer mejor su trabajo y el de la unidad a la que esté adscrito. En el mismo sentido, como consecuencia de la profesionalidad, nos encontramos con la diligencia, que supone hacer el trabajo bien, de forma cuidadosa y laboriosa. La receptividad subraya la capacidad da atender y de escuchar a los ciudadanos como rasgo inherente a la función pública en general, y a cada empleado en particular. Receptividad que incorpora la obligación de responder a las peticiones ciudadanas sin ampararse en el silencio administrativo, institución que refleja una grave patología administrativa que conviene curar. En este sentido, se entiende bien que se incluya la responsabilidad puesto que es lógico que el personal no se esconda bajo el amplio manto de la responsabilidad patrimonial de la Administración, sobre todo cuándo los daños ocasionados son consecuencia de su actuación dolosa o culposa en forma grave. 
La transparencia es un deber consecuencia del papel y funcionalidad de la Administración en las democracias puesto que son los ciudadanos los dueños de las instituciones públicas, de manera que sus dirigentes habrán de rendir cuentas de manera habitual. En el mismo sentido, las situaciones de confidencialidad han de estar plenamente justificadas.

Tras la enumeración de los principios, nos hallamos ante el repertorio de los deberes ya enumerados. Para terminar, procedería efectuar algunos comentarios a los deberes, que surgen de las ideas vertidas al glosar los principios sobre los que descansan.

Por lo que se refiere al deber de respeto a la Constitución, los Estatutos de Autonomía y al resto del Ordenamiento jurídico, me permito señalar que hubiera sido suficiente la apelación a la Constitución que, cómo sabemos engloba a las otras fuentes. Así incluso se obviaría la discusión sobre los principios generales. En cualquier caso, me parece de interés destacar la opinión de los redactores de que este deber ha de ser entendido como la " necesidad de un compromiso de todo empleado público con los valores y principios constitucionales, y muy especialmente, con el respeto y promoción de los derechos fundamentales en su actuación profesional". Es este un punto sobre el que vengo insistiendo desde mis primeras publicaciones de Ética pública y, ahora, al verlo reflejado en el informe, me alegra, no sólo porque es una idea de años atrás, sino porque es la médula de la función pública constitucional.

La referencia al deber de la imparcialidad nos exime, por su obviedad, de mayores comentarios. Solamente comentar la idea de los autores del dictamen sobre la posibilidad de ejercer discriminación positiva en los casos legalmente previstos. No me parece afortunada esta consideración por cuánto la figura, polémica dónde las haya, si es que alguna vez se puede aplicar ha de ser muy excepcionalmente y en unos supuestos muy tasados, lo que en la sociedad española, al menos para mí, y en los momentos presentes, es difícil de justificar. Por supuesto que en la imparcialidad va ínsita la objetividad; es decir, la referencia a la racionalidad y a la ponderación de los diferentes intereses en juego a partir de un principio general de motivación de los actos administrativos, así como la prohibición de cualquier tipo de discriminación de personas o grupos de personas. En el sentido del artículo 9.2 de la Constitución, se señala que los empleaos públicos han de promover la igualdad entre hombres y mujeres. Muy bien, aunque estaría mejor, por seguir con el artículo 9.2 que el mismo celo por la promoción de la igualdad se pusiera en la libertad, pues también a ella se refiere dicho precepto constitucional. 
El deber de obediencia se hace descansar sobre la jerarquía y también, me parece correcto, sobre la lealtad a la autoridades, reconociéndose la posibilidad de la desobediencia cuando las órdenes o instrucciones impartidas fueren manifiestamente ilegales. Aquí quizás el manifiestamente está de más. Si una orden es ilegal, es ilegal; ni es muy ilegal ni manifiestamente ilegal. El problema está en el procedimiento para hacer valer este deber de incumplir las órdenes ilegales. Si sólo sancionamos lo aparatosa y grandiosamente ilegal, corremos el peligro de pasar los asuntos que son "poco" ilegales, ilegales a fin de cuentas, y que tantas veces hacen más daño que las graves y palmarias ilegalidades. Preocupante, me parece, es la referencia, en sede de obediencia, a someterse al deber de control de los superiores que en cada caso corresponda. A mi este deber de someterse a control, así sin más matizaciones, me parece propio de un Estado policial. Es necesario modularlo y explicar en que materias se ejercerá ese control que, por otra parte y en lo referente al trabajo en la Administración pública, se presume implícito en la potestad de dirección.

El deber de trabajar con aplicación y diligencia está muy bien expresado. Mejor todavía, la referencia a que estos deberes incluyen también el de resolver en plazo los procedimientos administrativos quienes tengan esta competencia. Este es uno de los principales puntos negros de la Administración, no porque quien tiene que resolver en plazo no lo haga, sino porque a veces nos encontramos ante tramitaciones excesivamente largas que hacen imposible resolver en plazo. Igualmente, me parece acertado, aunque no se si este es el capítulo más adecuado, que quede claro que las tareas a encomendar sean las propias del grupo, categoría o especialidad, salvo por razones de urgencia o interés público superior.

En el marco del deber de colaboración, se insiste a la cooperación con jefes y compañeros y se subraya su dimensión dinámica desde el momento en que se incluye en él la formulación de sugerencias, propuestas o iniciativas que mejoren los fines y objetivos de la organización.

También el texto del informe se refiere a los deberes de cumplimiento del horario, de profesionalidad y a los de secreto y discreción profesional. Estoy de acuerdo con la expresión discreción en lugar de sigilo, y también es atinado plantear estos deberes en el marco de la obligación general de "informar al ciudadano (...) que obliga a los empleados a facilitar, sin ningún tipo de trabas, el acceso de los particulares a los documentos administrativos que tienen derecho a conocer, así como a facilitarles el ejercicio de sus derechos y el cumplimiento de sus obligaciones satisfaciendo las demandas de información al respecto. Deber éste que tiene también su fundamento en un principio ético de transparencia". 
El deber de integridad la Comisión de expertos lo entiende desde parámetros amplios: "deber que impide al empleado público contraer obligaciones económicas o de otro tipo con personas u organizaciones que puedan desviarle del cumplimiento de sus obligaciones". El deber de honestidad también aparece en el repertorio y se refiere a la obligación de declarar cualquier interés privado, propio, que se relaciones con el cumplimiento de sus funciones aunque no entrañe un conflicto de intereses. Junto a la integridad y honestidad, y derivado de ellos, surge la obligación de abstenerse en todos aquellos asuntos en los que el empleado tenga un interés personal.

La inclusión en el catálogo del deber de austeridad me parece, también, acertado. Este deber, en opinión de los expertos "exige utilizar los recursos y bienes públicos como si fueran propios, velando por su conservación y de acuerdo exclusivamente con los intereses públicos". Obviamente, la austeridad incluye la prohibición de usar bienes públicos en provecho propio o de personas afines.

Finalmente, los autores del informe se refieren a dos deberes de carácter laboral: el deber de formación que a todos los empleados compete para estar en mejores de hacer mejor el trabajo, y el deber de observar las normas de seguridad en el trabajo que pesa sobre cualquier empleado público o privado.

\section{REFLEXIÓN CONCLUSIVA}

La cuestión de los deberes del personal al servicio de las Administraciones públicas está hoy deficientemente tratado en la legislación de función pública. En realidad, la función pública lleva clamando desde la aprobación de la Constitución por el estatuto a que se refiere el artículo 103 de la Constitución.

Si hemos de esperar a que el estatuto vea la luz para disponer del catálogo de deberes del personal al servicio de las Administraciones públicas, podemos esperar demasiado tiempo, pues no parece que las circunstancias hayan variado tanto como para que en breves fechas se pueda aprobar el estatuto. ¿Qué podemos hacer, entonces? Podemos, por ejemplo, aprobar un código ético de la función pública que no parece pueda tener graves inconvenientes. En él se podrían enunciar los principios básicos a partir de los cuáles derivar un elenco de deberes. 